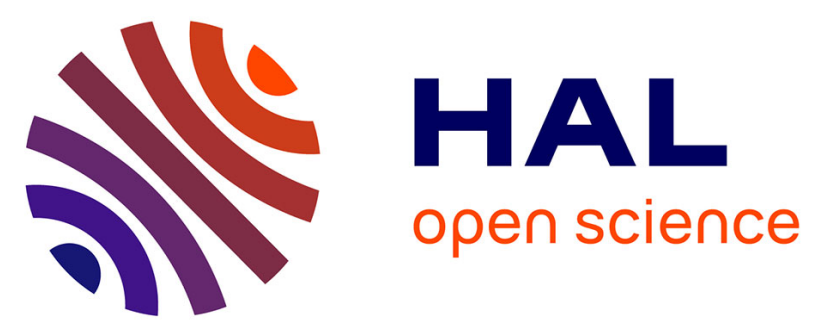

\title{
Stir bar sorptive extraction coupled to liquid chromatography-tandem mass spectrometry for the determination of pesticides in water samples: method validation and measurement uncertainty C. Margoum, C. Guillemain, X. Yang, Marina Coquery
}

\section{To cite this version:}

C. Margoum, C. Guillemain, X. Yang, Marina Coquery. Stir bar sorptive extraction coupled to liquid chromatography-tandem mass spectrometry for the determination of pesticides in water samples: method validation and measurement uncertainty. Talanta, 2013, 116, p. 1 - p. 7 . 10.1016/j.talanta.2013.04.066 . hal-00838263

\section{HAL Id: hal-00838263 \\ https://hal.science/hal-00838263}

Submitted on 25 Jun 2013

HAL is a multi-disciplinary open access archive for the deposit and dissemination of scientific research documents, whether they are published or not. The documents may come from teaching and research institutions in France or abroad, or from public or private research centers.
L'archive ouverte pluridisciplinaire HAL, est destinée au dépôt et à la diffusion de documents scientifiques de niveau recherche, publiés ou non, émanant des établissements d'enseignement et de recherche français ou étrangers, des laboratoires publics ou privés. 
Stir bar sorptive extraction coupled to liquid chromatography-tandem mass spectrometry for the determination of pesticides in water samples: method validation and measurement uncertainty

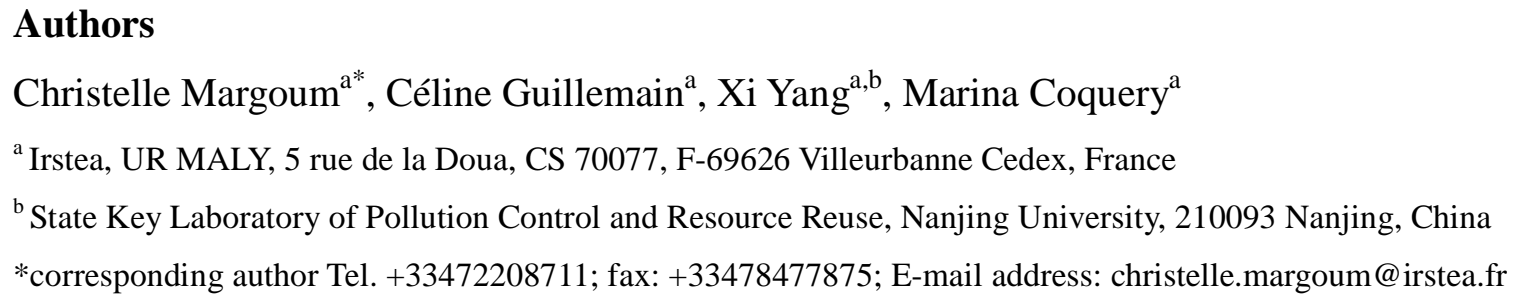

Stir bar sorptive extraction followed by liquid desorption and high performance liquid chromatography with tandem mass spectrometry (SBSE-LD-LC-MSMS) has been developed for the determination of 15 pesticides or selected metabolites from different families (herbicides, insecticides, fungicides) in surface water samples. The optimization of parameters that could influence SBSE-LD efficiency was carried out by means of experimental design. Optimized conditions were established as follows concerning extraction time, stirring speed, aqueous medium characteristics (ionic strength and polarity) and back desorption solvent and time, respectively: $3 \mathrm{~h}$ (800 rpm), addition of 10\% of sodium chloride, no addition of methanol as organic modifier, and 15 min ultrasonic desorption in equivolume mixtures of acetonitrile-methanol. A specific and thorough cleanup procedure was developed and applied to each stir bar to avoid possible carry-over between consecutive extractions with the same stir bar. Pesticide quantification in water was achieved thanks to matrix matched calibration. Mean recoveries ranged from 93 to $101 \%(\mathrm{RSD}<17 \%, \mathrm{n}=30)$. Validated limits of quantification in matrix were between 0.02 and $1 \mu \mathrm{g} \mathrm{L}^{-1}$, depending on the compound. A specific experimental design was conducted to evaluate the measurement uncertainty, which was comprised between 13 and $51 \%$, whatever the pesticide and the concentration level. The applicability of the SBSE-LD-LCMSMS method was evaluated by analyzing surface water samples and by comparing with conventional solid phase extraction-LC-MSMS procedure.

Keywords: stir bar sorptive extraction (SBSE), liquid chromatography-tandem mass spectrometry (LCMSMS), pesticides, surface water, validation, measurement uncertainty 


\section{Introduction}

Organic compounds from aqueous sample matrices can be analyzed by various extraction and

enrichment methods such as liquid-liquid extraction, solid phase extraction (SPE), or headspace and purge-and-trap techniques for the most volatile compounds [1]. In combination with liquid chromatography, SPE is the most common technique for the extraction of dissolved organic compounds in environmental water samples. In the past two decades, analytical chemists gave much attention to solvent-free sample preparation techniques, namely green techniques that are based on sorptive extraction using a polymeric stationary phase. Those techniques include solid phase micro-extraction (SPME) and stir bar sorptive extraction (SBSE). Indeed, sorptive extraction has proven to be an interesting technique as it requires little quantity of water samples and organic solvents, and then it is an environmentally friendly alternative to liquid extraction or solid phase extraction [2]. The most widely used sorptive extraction phase is polydimethylsiloxane (PDMS) [3]. The main difference between SPME and SBSE is the much larger volume of PDMS used in the latter, which results in higher recoveries and higher sample capacity [4]. In contrast to extraction with adsorbents in which the analytes are bound to the active sites on a surface, not only the surface area but also the total amount of the extraction phase are important in sorptive extraction. After the extraction step, the solutes can be introduced quantitatively into the analytical system by thermal desorption (TD) or after liquid desorption (LD) [5]. Recent literature reviews the satisfactory use of SBSE for the extraction of several organic contaminants, including dissolved pesticides, in environmental waters $[4,6]$. Although LCMSMS has become the method of choice for analyzing traces of pesticides in environmental matrices, studies on SBSE coupled to this high-performance technique are scarce [7]. The stir bars can be used for several and consecutive extractions, but it is surprising to note that only few method developments proposed efficient cleanup procedure to ensure stir bar decontamination [8,9]. In addition to method validation, measurement uncertainty is a quantitative indicator of the confidence in the analytical data as it describes the range around the result within which the true value can be expected. As no specific proficiency tests are available for SBSE analysis, within-laboratory evaluation is required. Leon et al [10] determined the overall uncertainties for SBSE coupled to thermal desorption and analysis of 35 organic micropollutants, pesticides and polycyclic aromatic hydrocarbons (PAHs) with GCMS. To our knowledge, there is no study aiming at evaluating uncertainties for SBSE-LD-LC-MSMS.

$$
\text { In this context, the aim of this paper was to present the optimization and validation of a robust }
$$


method for the determination of low level concentrations of pesticides in surface water samples combining SBSE and LC-MSMS analysis. Fifteen pesticides or metabolites from different families (herbicides, insecticides and fungicides) were selected for this study according to their use and occurrence in the surface waters of agricultural watersheds in France. Laboratory studies were conducted according to Designs of Experiments (DoE) to optimize the main parameters which could influence SBSE-LD efficiency, particularly the extraction profile (time and stirring speed), the aqueous medium characteristics (ionic strength and polarity) and the back-desorption solvents and time. The performances of the optimized method were evaluated in terms of linearity, limits of quantification, precision and trueness. Analytical uncertainties were also assessed by means of a specific withinlaboratory experimental design. In addition, we study the conservation of the pesticides sorbed on stir bars stored under different conditions. Finally, we applied this extraction method for the analysis of pesticides in surface water and compared results with parallel analyses using SPE coupled to LCMSMS.

\section{Experimental section}

\subsection{Chemicals and materials}

Certified standard chemicals were used (purity $\geq 92.5 \%$ ). Azoxystrobin (AZS), chlorfenvinphos (CFV), chlorpyrifos (CPE), diuron (DIU), 3,4-dichloroaniline (DCA), 3-(3,4-dichlorophenyl)-1methylurea (DCPMU), diflufenican (DFF), dimethomorph (DMM), fenitrothion (FNT), isoproturon (IPU), linuron (LINU), norflurazon (NFZ), procymidone (PCM), spiroxamine (SPX), tebuconazole (TBZ) were supplied from Cluzeau Info Labo (Sainte-Foy-La-Grande, France) for standard solutions or from Sigma Aldrich (Saint-Quentin Fallavier, France) for quality control solutions. Isoproturon d6 and diuron d6 (Dr Ehrenstorhfer from VWR, Strasbourg, France) were added as surrogate and injection internal standard respectively. Sodium chloride ( $\mathrm{NaCl}, 99-100.5 \%)$ was supplied from SDS (Peypin, France).

Analytical or LC-MS grade organic solvents, namely acetonitrile, methylene chloride and methanol were purchased from VWR (Strasbourg, France). Formic acid (purity 98\%) for LC-MS analysis was provided by Sigma Aldrich (Saint Quentin Fallavier, France). Ultrapure water was obtained from Milli$\mathrm{Q}^{\circledR}$ water purification system connected to a LC-PAK cartridge to remove remaining organic 
contaminants at trace levels (Millipore, Molsheim, France).

The individual stock solutions were prepared in acetone at a concentration of $100 \mathrm{mg} \mathrm{L}^{-1}$ and stored at $4^{\circ} \mathrm{C}$. These stock solutions were stable for two months. Standard working solutions at various concentrations were prepared daily by appropriate dilutions of the stock solutions in Milli-Q water.

\subsection{Liquid chromatography tandem mass spectrometry analysis}

Liquid chromatography was performed on an Agilent series 1100 HPLC system (Agilent Technologies, USA). The analytes were separated on a C18 Atlantis T3 (100 mm x $2.1 \mathrm{~mm}$ x $3 \mu \mathrm{m}$ particle size) from Waters (Saint Quentin en Yvelines, France). The column temperature was set at $30^{\circ} \mathrm{C}$. The injection volume was $20 \mu \mathrm{L}$. Liquid chromatography was carried out using the mobile phases A (water) and B (acetonitrile), both containing $0.1 \%$ formic acid. The gradient was performed as follows: 10\% B (initial composition) modified to $90 \%$ B over 10 min, and re-equilibrated at $10 \%$ B for $5 \mathrm{~min}$ between runs. The flow rate of the mobile phase was set at $400 \mu \mathrm{L} \mathrm{min}{ }^{-1}$.

The HPLC system was coupled to a triple-quadrupole mass spectrometer (API 4000, AB Sciex, Les Ulis, France). Optimization of the ion source and MS/MS settings were performed by the automatic optimization function of the MS software (Analyst 1.5.1, AB Sciex), assisted by manual optimization using infusion with a syringe-pump and flow injection of standard solutions. The electrospray ion source (Turbo-Ionspray, AB Sciex) was operated in the positive mode at $600^{\circ} \mathrm{C}$. The ion spray voltage was $+5500 \mathrm{~V}$. Nitrogen was used as curtain and collision gas, while air was used as nebulizer and drying gas. In the multiple reaction monitoring (MRM) mode, the mass spectrometer is detecting ions by monitoring the dissociation of the given precursor ions to the product ions of specific masses. The analyzed pesticides were identified and confirmed by their specific retention times, two characteristic precursor-product ion transitions (quantifier and qualifier), and specific ratios of the intensities of the product ions in compliance with European Commission Decision 2002/657/EC [11]. The relevant instrument settings for each precursor-product ion transition are shown in Table 1. For each compound, the first product ion was used for quantification and the second one for confirmation. Quantification was performed with deutered diuron d6, used as injection internal standard (IS). Matrix-matched calibration curves with relative areas versus internal standard (IS) area were used for quantification in spiked and natural samples. This methodology allows to take into account recoveries for each batch and to compensate for possible matrix effects. 


\subsection{Development of the stir bar sorptive extraction and the cleanup procedure}

The stir bars (Twister ${ }^{\circledR}$ from Gerstel, Müllheim, Germany) are coated over $20 \mathrm{~mm}$ of their length with a $1.0 \mathrm{~mm}$ film of PDMS $(126 \mu \mathrm{L})$. Before use, each stir bar was first thermally conditioned at $50^{\circ} \mathrm{C}$ for 24 hours, then put into a glass tube containing $10 \mathrm{~mL}$ of mixed solvent methanol/methylene chloride $(50: 50, \mathrm{v} / \mathrm{v})$ and treated for $30 \mathrm{~min}$ by sonication. The clean stir bar was then removed from the solvent solution and dried at $50{ }^{\circ} \mathrm{C}$ for one more hour.

In a typical assay, a stir bar was immersed into a $30 \mathrm{~mL}$ amber vial containing $20 \mathrm{~mL}$ of pre-filtered water sample ( $0.7 \mu \mathrm{m}$ on GF-F glass fiber filters, Whatman). The vial was closed with a PTFE/silicone screw cap. The extraction with stir bars was performed at room temperature on a magnetic agitator (Variomag Multipoint 15, H+P Labortechnik AG, Germany). The stir bar was removed from the water sample, cleaned with ultrapure water, dried with a lint-free tissue and stored at $-18^{\circ} \mathrm{C}$ for at least 24 hours. For the desorption step, the stir bar was placed into a $250 \mu \mathrm{L}$-glass flat bottom insert, which was filled with $200 \mu \mathrm{L}$ of back-desorption solvent. Back desorption of the analytes by organic solvents was achieved by ultrasonic treatment of these vials in an ultrasonic bath (FB11014, Fisher Scientific, UK) for 15 min. Ice was continuously added to the bath to adjust and maintain its temperature at about $20^{\circ} \mathrm{C}$. In a $250 \mu \mathrm{L}$-glass insert, $40 \mu \mathrm{L}$ of the previous organic extract was added to $150 \mu \mathrm{L}$ of ultrapure water spiked with $10 \mu \mathrm{L}$ of internal standard solution (diuron d6 at a concentration of $200 \mu \mathrm{g} \mathrm{L}^{-1}$ ). This solution was homogenized before analysis by LC-MSMS.

After back desorption step, the stir bars were reconditioned by sonication during $30 \mathrm{~min}$ in $10 \mathrm{~mL}$ of methanol/acetonitrile $(50: 50, \mathrm{v} / \mathrm{v})$, then in $10 \mathrm{~mL}$ of methanol/methylene chloride $(50: 50, \mathrm{v} / \mathrm{v})$ and finally dried overnight at $50^{\circ} \mathrm{C}$. This complete cleanup procedure, applied to each stir bar before and after extraction, allowed to efficiently clean the stir bar before re-use. Contamination levels on the clean stir bars were regularly controlled by analyzing blanks; and we noticed that stir bars could not be reused after extraction of water sample containing at least one pesticide with concentration higher than $10 \mu \mathrm{g} \mathrm{L}{ }^{-1}$.

\subsection{Optimization of the extraction procedure}

We first established the SBSE-LD experimental conditions that would provide high recovery yields 
160 and good precision for the pesticides. For the development step, studies were carried out with pure

161 water spiked with a selection of pesticides. The main parameters which could influence SBSE-LD

162 efficiency were optimized: extraction profile (time and stirring speed), aqueous medium characteristics

163 (ionic strength and polarity) and back-desorption solvents and time [6, 12]. Considering the selected

164 pesticides are mostly in nonionic form at $\mathrm{pH}$ values of surface water, $\mathrm{pH}$ was not considered as a 165 relevant parameter to be taken into account in this study. Designs of Experiments (DoE) methodology 166 was used to optimize the pre-selected factors and to evaluate the interaction between different variables 167 of SBSE process. Statgraphics Centurion XV (version 15.2.06) from SIGMA PLUS (Toulouse, France) 168 was used to plan the experiments and for the treatment of the results. A multi-response strategy was 169 used for the optimization of the method.

\subsection{Stir bar conservation study}

A specific study was carried out to test the conservation of pesticides sorbed on the stir bars under different conditions. Samples of Evian mineral water were spiked with all the studied pesticides at $1 \mu \mathrm{g}$ $\mathrm{L}^{-1}$ and were extracted with four triplicates of stir bars. After extraction, one triplicate of stir bars was desorbed and analyzed subsequently (T0) whereas the other triplicates of stir bars were stored in a brown glass vial under different conditions before chemical analysis. The second triplicate of stir bars was stored during 2 days at ambient temperature $\left(20^{\circ} \mathrm{C}\right)$, the third one was kept refrigerated during 7 days at $4^{\circ} \mathrm{C}$ and the forth one was frozen at $-18^{\circ} \mathrm{C}$ for 7 days.

\subsection{Method validation and measurement uncertainty}

Within-laboratory validation was performed to evaluate the analytical performances of the SBSE-LDLC-MSMS according to the following criteria: linearity, limit of quantification (LOQ), precision and trueness, inspired from reference standards (ISO/IEC 17025:2005, AFNOR NF T90-210:2009, SANCO/10684/2009) [13-15].

The linear dynamic range of the method was determined under optimized experimental conditions with matrix-matched standards $(\mathrm{n}=5)$. Pure water $(20 \mathrm{~mL})$ was spiked at 6 different concentration levels of pesticides covering all the dynamic range. Linearity was assumed when correlation coefficient $\left(\mathrm{r}^{2}\right)$ was 
192 higher than 0.990 with bias lower than the maximum acceptable deviation fixed between 10 and $50 \%$

193 depending on the concentration level.

194 For each pesticide, a predetermined LOQ value was first evaluated according to the sensibility of the 195 lowest standard concentration (analytical signal to noise $(\mathrm{S} / \mathrm{N})$ ratio fixed at 10 ), then verified with at 196 least 2 spiked samples (Evian mineral water) and readjusted if the recovery was out of the range 60$197110 \%$. The proposed LOQ value was confirmed with 5 replicates of natural water samples spiked at the 198 predetermined concentration. Mean concentration $(\overline{L O Q})$ and standard deviation $\left(\mathrm{s}_{\mathrm{LOQ}}, \mathrm{n}=10\right)$ were 199 calculated and compared to a fixed maximum acceptable deviation (60\% of the spiking value $\left.\mathrm{LOQ}_{\mathrm{ref}}\right)$. 200 For each pesticide, the two following equations had to be verified:

The mean recoveries and corresponding relative standard deviation (RSD) were calculated for trueness and precision evaluation at three different concentration levels, corresponding to the LOQ level, to a medium and to a high concentration level of the calibration curves. Five replicates were performed for each level under within-laboratory reproducibility conditions. The determination of the measurement uncertainty must take into account all sources of errors in the analytical process (operator, standard preparation, sample origin, different days and different equipments if possible) [16]. SBSE-LD-LCMSMS uncertainties were assessed for several water samples of various nature (Evian mineral water, natural surface waters collected in different rivers in France and ultrapure water) spiked at three concentration levels. A specific experimental design was achieved with 10 triplicates for each concentration level under within-laboratory reproducibility conditions, according to reference standards $[16,17]$. Measurement uncertainty was assessed at 3 different concentration levels covering the whole dynamic range. For each level, the uncertainty was evaluated using the within-laboratory reproducibility relative standard deviation. An expanded coverage factor of $\mathrm{k}=2$ was used to calculate the expanded uncertainty with a confidence interval of 
Natural surface water samples were collected in a small river contaminated with pesticides [18]. Water samples were filtered on glass fibre filters $(0.7 \mu \mathrm{m}$ GF-F, Whatman). Solid phase extraction was performed with Oasis HLB cartridge $(60 \mathrm{mg}, 3 \mathrm{~mL})$ from Waters (Guyancourt, France). Deutered diuron d6 was used as internal standard for the quantification. The concentration factor was 1000 .

\section{Results and discussion}

\subsection{Optimization of liquid desorption (LD) efficiency}

\subsubsection{Solvent composition and back-extraction time for $L D$}

For the method development, we started by evaluating the LD conditions to ensure optimal backextraction of the pesticides. According to some authors, non-polar solvents such as isooctane strongly partition into the PDMS phase [1, 19]. Hence, we avoided these solvents in LD experiments. We set the following SBSE conditions: $20 \mathrm{~mL}$ of water sample were agitated for $3 \mathrm{~h}$ at $800 \mathrm{rpm}$, without any adjustment of ionic strength or polarity of the sample solution. We explored recoveries of pesticides at the $1 \mu \mathrm{g} \mathrm{L}^{-1}$ level using different desorption times under sonication $(5,15,30 \mathrm{~min})$; and solvent ratios $(\mathrm{v} / \mathrm{v})$ of acetonitrile $(\mathrm{ACN})$ and methanol $(\mathrm{MeOH})(100: 0,50: 50,0: 100)$. These pre-selected conditions are in accordance with other studies from literature, as methanol and acetonitrile are the most common desorption solvents [6, 7] and sonication is used to accelerate LD [7, 19]. Recovery of an individual pesticide was calculated as the peak area ratio (\%) between the samples injected into the LC-MSMS system after and before the SBSE-LD treatment (Table 2). From these results, the multi-response optimization of the design using Statgraphics Centurion XV showed that the maximum recoveries were obtained with a desorption time of 15 min under sonication with $\mathrm{ACN} / \mathrm{MeOH}$ (50:50, v/v) as backextraction solvent.

\subsubsection{Optimization of extraction efficiency}

According to SBSE theory [2], equilibrium of the analytes between the PDMS polymeric coating of the stir bar and water matrix correlates strongly with the hydrophobic characteristics of analytes. Extraction time is one of the most important conditions affecting this equilibrium. Experiments to 
estimate the most suitable equilibrium time were performed by making assays from 1 to $5 \mathrm{~h}$ for all the pesticides, at room temperature. Ionic strength is another important factor that can play a decisive role in enhancing extraction efficiency. An increase in ionic strength reduces the affinity of the aqueous matrix for the more polar analytes in comparison with the affinity of the PDMS coating of the stir bar [19]. Consequently, the amount of pesticides extracted by the stir bar could be increased if the solubility of these analytes in water is reduced by addition of salt to change the ionic strength of the medium. However, because high salt concentrations could affect the stability of PDMS [20], the salting-out effect was tested by addition of only 5 or $10 \%(w / v)$ of sodium chloride. Although efficient stirring can enhance recovery of SBSE, a high stirring speed could, however, affect mass transfer of the analytes into the PDMS phase during the equilibrium process, resulting in lower recoveries for some compounds [1]. In our experiments, when stirring $20 \mathrm{~mL}$ of water sample in a $30 \mathrm{~mL}$ vial, a stirring speed above $800 \mathrm{rpm}$ may cause unstable agitation of the stir bar. SBSE efficiency of the studied pesticides was thus evaluated through experiment design with the following factors and levels: stirring speed, $500 \mathrm{rpm}$ and $800 \mathrm{rpm}$; extraction time, 1, 3 and $5 \mathrm{~h}$; salt concentration $\mathrm{NaCl} \mathrm{0,5}$ and 10\% (w/v). When stirring speed was increased from $500 \mathrm{rpm}$ to $800 \mathrm{rpm}$, recovery of each pesticide after $3 \mathrm{~h}$ extraction was enhanced, except for diuron for which a slight decrease in recovery was observed (results not shown). Thus, we set $800 \mathrm{rpm}$ as the stirring speed for further SBSE assays. Figure 1 shows the recoveries for 8 selected pesticides obtained with the different extraction times (from $1 \mathrm{~h} \mathrm{to} 5 \mathrm{~h}$ ) and with addition of $10 \% \mathrm{NaCl}$ or not. Whatever the other conditions, the recoveries increased with time for all the pesticides with the addition of $\mathrm{NaCl}$. For TBZ, the recovery decreased when extraction was performed during $5 \mathrm{~h}$ with $\mathrm{NaCl}$. The same observation has been made for other hydrophobic compounds with $\log$ Kow $>3$ [6]. For further SBSE assays, an extraction time of $3 \mathrm{~h}$ and addition of $10 \% \mathrm{NaCl}$ were chosen.

Analyte adsorption on the vial glass walls is a phenomenon that can occur. When it happens, the sorption efficiency decreases, particularly for the most hydrophobic compounds at trace levels [21]. Notwithstanding the fact that an organic modifier slightly increases the solubility of hydrophobic compounds in aqueous media, this could be an important parameter to consider, as it could help preventing undesirable adsorption on the vial glass walls, according to several authors [22-24]. In our experiments, the addition of $\mathrm{MeOH}$ had an opposite effect according to whether we added $\mathrm{NaCl}$ or not. With $\mathrm{NaCl}$ in the sample, the presence of $\mathrm{MeOH}$ decreased recoveries; in contrast, when no $\mathrm{NaCl}$ was added, increasing the amount of $\mathrm{MeOH}$ from 0 to $10 \%$ slightly enhanced recovery yield of all pesticides under this study. However, because the salt-effect was more significant, further experiments 
were performed without $\mathrm{MeOH}$ addition.

\subsubsection{Optimized SBSE-LD conditions}

The optimized conditions were established as follows concerning water ionic strength, stirring time and speed, and desorption solvent and time, respectively: $10 \%$ of $\mathrm{NaCl}$ were added to $20 \mathrm{~mL}$ of prefiltered water, extraction was performed during $3 \mathrm{~h}$ at $800 \mathrm{rpm}$ and desorption was carried out with 200 $\mu \mathrm{L}$ of $\mathrm{ACN} / \mathrm{MeOH}(50: 50, \mathrm{v} / \mathrm{v})$ during $15 \mathrm{~min}$ under sonication at room temperature. These experimental optimized conditions were used for the validation step and the uncertainty evaluation.

\subsection{Stir bar conservation study}

For each studied pesticide, the relative recovery of the 3 different storage conditions (in comparison with T0) and the corresponding standard deviation $(n=3)$ are reported on Figure 2.

The storage of the stir bars during 2 days at ambient temperature was not relevant as the relative recoveries obtained for some hydrophobic compounds were either lower (i.e., chlorpyriphos) or higher than 1 (i.e., chlorfenvinphos, fenitrothion). Two pesticides (procymidone, DCPMU) were not detected after storage for 7 days at $4^{\circ} \mathrm{C}$; we can suspect a degradation of these molecules. The relative recovery obtained for fenitrothion is 2 fold higher at $-18^{\circ} \mathrm{C}$ than at $4^{\circ} \mathrm{C}$ for the same duration of storage (7 days). In addition, the storage conditions seemed to have an impact on the variability of the recoveries. Indeed, considering all the pesticides, mean standard deviation was 0.12 at T0, 0.20 for the frozen stir bars, 0.22 for the refrigerated stir bars and 0.32 for the stir bars stored at ambient temperature.

Finally, freezing appeared as the best storage condition for the studied pesticides as no degradation of the pesticides sorbed on the stir bars was observed. Camino-Sánchez et al [25] also mentioned (results not shown in their paper) that the stir bars can be stored frozen without any degradation of the 77 priority persistent organic pollutants studied. As the water samples containing pesticides have to be extracted as soon as possible after sampling, all the stir bars used for the extraction of the water samples and for the matrix match calibration curve can be frozen just after extraction. This additional conservation step allows to delay the analysis by LC-MSMS.

\subsection{Validation of the SBSE-LD-LC-MSMS method}


The SBSE-LD-LC-MSMS method was validated based on quality criteria indicated in Section 2.4. A remarkable linearity was attained $\left(r^{2}>0.998\right)$ for all the studied pesticides (Table 3$)$. For each calibration curve, the observed bias was between $10 \%$ for the highest concentration level and $50 \%$ for the lowest one.

The sample matrix could influence the partition process of SBSE. Matrix effects were examined by comparison of calibration curves obtained with SBSE extraction of spiked ultrapure water and filtered natural river water collected in a non contaminated upstream site. The difference between the slope of the matrix match calibration curves was always less than $10 \%$, except for isoproturon (13\%) (results not shown). Matrix effect was considered as non-significant. Thus, for quantification purpose, calibration curves can be achieved with any type of water.

The validated limits of quantification (LOQ) in water ranged from 0.02 to $1 \mu \mathrm{g} \mathrm{L}^{-1}$ depending on the compound. The lowest LOQ $\left(0.02 \mu \mathrm{g} \mathrm{L}^{-1}\right)$ was obtained for azoxystrobine and spiroxamine, whereas diuron and its main metabolite DCPMU had a validated LOQ of $1 \mu \mathrm{g} \mathrm{L}^{-1}$. This can be explained by the very low row recoveries obtained for these 2 compounds without a matrix match calibration curve (Table 2). In the literature, the LOQ is often defined as the concentration giving a signal to noise ratio of 10 . The LOQ reported in this work and validated in natural water matrix were similar to those described elsewhere after SBSE-LD-LCMSMS determination [7]. The LOQ evaluated by Giordano et al. were $0.6 \mu \mathrm{g} \mathrm{L}^{-1}$ for diuron, $0.1 \mu \mathrm{g} \mathrm{L}^{-1}$ for chlorfenvinphos and $1.5 \mu \mathrm{g} \mathrm{L}^{-1}$ for chlorpyrifos. Lower LOQ at the $n g \mathrm{~L}^{-1}$ level can be reached for organic contaminants that can be analyzed by gas chromatography and thermal desorption [6].

The method accuracy was evaluated in terms of precision and trueness at the three different spiking levels under within-laboratory reproducibility conditions (Table 3). Trueness was calculated in terms of recovery. Considering all the concentration levels, mean recoveries obtained with matrix-match calibration curves were in the range of $93-101 \%$ (Table 3). Global inter-day precision was estimated as RSD (\%) of 30 determinations and was between 9 and $17 \%$ for each pesticide. These values are comparable to those reported in the literature by Prieto et al. (repeatability usually <16\%) [6]. It is also important to highlight that, no difference was noticed for trueness or precision between the LOQ level and higher concentration levels.

Results on measurement uncertainty are reported in Table 3. Measurement uncertainty for SBSELD-LC-MSMS was less than $25 \%$ for all pesticides at the 3 concentration levels. To our knowledge, no determination of the measurement uncertainty has been reported for SBSE-LD-LC-MSMS methods. The values obtained in the present study are in accordance with the scarce data found in the literature 
351 regarding the analysis of organic compounds by SBSE coupled with thermal desorption and GC-MS analysis $[10,25]$,

\subsection{Applicability of the SBSE-LD-LC-MSMS method to surface water samples}

A first batch of experiments consisted in analyzing pre-filtered surface waters with SBSE-LD-LCMSMS and to compare the results with conventional SPE-LC-MSMS using Oasis HLB cartridge. As presented on Figure 3, within the concentration range between LOQ and $10 \mu \mathrm{g} \mathrm{L}^{-1}$, acceptable similarity was obtained for the measurement of pesticides between the two procedures. The difference in concentrations varies between $3 \%$ (for tebuconazole TBZ in sample A) and 60\% (for DCPMU in sample A, with a concentration value just above the LOQ of the SBSE method), with a mean difference of $24 \%$ when considering all the quantified pesticides and the samples. The comparison between the 2 techniques can also be done in terms of sensitivity. Due to the higher concentration factor, SPE is much more sensitive than SBSE for diuron and DCPMU with LOQ of 1 and $0.02 \mu \mathrm{g} \mathrm{L}^{-1}$ for SBSE and SPE respectively. For tebuconazole and dimethomorph, LOQ obtained with SBSE are in the same order of magnitude than with SPE. For azoxystrobin, the two LOQ are similar $\left(0.02\right.$ and $0.025 \mu \mathrm{g} \mathrm{L}^{-1}$ for SBSE and SPE respectively). Except for diuron and DCPMU, the use of SBSE followed by liquid desorption and LCMSMS quantification leads to similar LOQ to conventional SPE that requires a larger volume of water sample.

In a second time, concentrations of targeted and only detected pesticides are reported on Figure 4 for 2 different water samples that were previously filtered or not. Suspended particulate matter rate was $<2 \mathrm{mg} \mathrm{L}^{-1}$ and $10 \mathrm{mg} \mathrm{L}^{-1}$ for sample 1 and 2 respectively. No difference in pesticide concentrations was observed whatever the suspended particulate matter rate. In our study, extraction of surface waters with stir bar allowed to efficiently analyze pesticides in the dissolved phase but did not take into account pesticides sorbed onto particulate matter. This is in contradiction with the results of Barco-Bonilla for more hydrophobic compounds such as polycyclic aromatic hydrocarbons in wastewaters effluents containing low and high amounts of suspended particulate matter (concentrations not specified in the paper) [26].

\section{Conclusions}


A stir bar sorptive extraction and liquid desorption method followed by high performance liquid chromatography with tandem mass spectrometry (SBSE-LD-LC-MSMS) was successfully developed and validated for the determination of 15 different pesticides (log Kow from 2.5 to 3.7) in natural water matrices, at trace level concentrations. We showed that the stir bars can be frozen after extraction to stabilize the compounds and to give more flexibility to the laboratories. A complete and efficient cleanup step was developed to avoid carry-over and to ensure that the stir bars are clean for successive applications. Good analytical performances were attained for all the studied pesticides, including an excellent linear dynamic range and a suitable precision. The LOQ validated in real water matrices ranged from 0.02 to $1 \mu \mathrm{g} \mathrm{L}^{-1}$ with associated uncertainty always below $25 \%$. Hence, this reliable and relatively simple extraction method could be considered as an alternative to more conventional extraction procedure such as SPE for a rapid screening of water contamination. In addition, SBSE followed by thermal desorption coupled to GC-MSMS is also being developed for more hydrophobic pesticides to achieve lower LOQ.

\section{Acknowledgements}

This work was partly supported by the Pôle de Compétitivité Axelera (Chimie, Environnement)Projet Rhodanos and by the French National Agency for Water and Aquatic Environments (ONEMA). The authors want to thank the French-Chinese Foundation for Sciences and their Applications and the National Natural Science Foundation of China (No. 50578074) for financial support for a grant and L. Liger, O. Garcia, B. Motte and A. Assoumani of Irstea (UR MALY, Lyon) for their help during river water sampling and data processing.

\section{References}

[1] P. Popp, C. Bauer, L. Wennrich, Analytica Chimica Acta, 436 (2001) 1-9.

[2] E. Baltussen, P. Sandra, C. Cramers, F. David, Journal of Microcolumn Separations, 11 (1999) 737-747.

[3] R. Lucena, Analytical and Bioanalytical Chemistry, 403 (2012) 2213-2223.

[4] F. Sánchez-Rojas, C. Bosch-Ojeda, J. Cano-Pavón, Chromatographia, 69 (2009) 79-94.

[5] M. Kawaguchi, R. Ito, K. Saito, H. Nakazawa, Journal of Pharmaceutical and Biomedical Analysis, 40 (2006) $500-508$.

[6] A. Prieto, O. Basauri, R. Rodil, A. Usobiaga, L.A. Fernández, N. Etxebarria, O. Zuloaga, Journal of Chromatography A, 1217 (2010) 2642-2666.

[7] A. Giordano, M. Fernandez-Franzon, M.J. Ruiz, G. Font, Y. Pico, Analytical and Bioanalytical Chemistry, 393 (2009) 1733-1743.

[8] M. Bourdat-Deschamps, J.J. Daudin, E. Barriuso, Journal of Chromatography A, 1167 (2007) 143-153.

[9] E.D. Guerrero, R.C. Mejias, R.N. Marin, C.G. Barroso, Journal of Chromatography A, 1165 (2007) 144-150.

[10] V.M. Leon, J. Llorca-Porcel, B. Alvarez, M.A. Cobollo, S. Munoz, I. Valor, Analytica Chimica Acta, 558 (2006) 261266. 
421 [11] European_Commission, Off. J. European Union, , L221 (2002) 8-36.

422 [12] P. Serôdio, M.S. Cabral, J.M.F. Nogueira, Journal of Chromatography A, 1141 (2007) 259-270.

423 [13] SANCO/12495/2011, in, 2012, pp. 41.

424 [14] AFNOR, in, 2009, pp. 43.

425 [15] International_Organization_for_Standardization, in, 2005.

426 [16] International_Organization_for_Standardization, in, 2012, pp. 26.

427 [17] AFNOR, in, 2003, pp. 74.

428 [18] M. Rabiet, C. Margoum, V. Gouy, N. Carluer, M. Coquery, Environ. Pollut., 158 (2010) 737-748.

429 [19] P. Serodio, J.M.F. Nogueira, Analytical and Bioanalytical Chemistry, 382 (2005) 1141-1151.

430 [20] F. Hernandez, J. Beltran, F.J. Lopez, J.V. Gaspar, Analytical Chemistry, 72 (2000) 2313-2322.

431 [21] J. Vercauteren, C. Peres, C. Devos, P. Sandra, F. Vanhaecke, L. Moens, Analytical Chemistry, 73 (2001) $1509-1514$.

432 [22] C. Almeida, J.M.F. Nogueira, Journal of Pharmaceutical and Biomedical Analysis, 41 (2006) 1303-1311.

433 [23] V.M. León, B. Álvarez, M.A. Cobollo, S. Muñoz, I. Valor, Journal of Chromatography A, 999 (2003) 91-101.

434 [24] P. Serodio, J.M.F. Nogueira, Analytica Chimica Acta, 517 (2004) 21-32.

435 [25] F.J. Camino-Sánchez, A. Zafra-Gómez, S. Cantarero-Malagón, J.L. Vílchez, Talanta, 89 (2012) $322-334$.

436 [26] N. Barco-Bonilla, R. Romero-González, P. Plaza-Bolaños, J.L. Fernández-Moreno, A. Garrido Frenich, J.L. Martínez 437 Vidal, Analytica Chimica Acta, 693 (2011) 62-71. 
441

442

443

444

Table 1

Multiple reaction monitoring conditions for MS/MS analysis of the selected pesticides

\begin{tabular}{|c|c|c|c|c|c|c|c|}
\hline Compound & Abbreviation & $\begin{array}{l}\text { Precursor } \\
\text { ion }(\mathrm{m} / \mathrm{z})\end{array}$ & $\begin{array}{l}\text { Declustering } \\
\text { potential (V) }\end{array}$ & $\begin{array}{l}\text { Product } \\
\text { ions } \\
(\mathrm{m} / \mathrm{z})\end{array}$ & $\begin{array}{l}\text { Collision } \\
\text { energy } \\
\text { (V) }\end{array}$ & $\begin{array}{l}\text { Collision } \\
\text { cell exit } \\
\text { potential } \\
(\mathrm{V})\end{array}$ & $\begin{array}{l}\text { Dwell } \\
\text { time } \\
\text { (msec) }\end{array}$ \\
\hline \multirow[t]{2}{*}{ azoxystrobin } & AZS & 403.9 & 61 & 372.0 & 21 & 22 & 25 \\
\hline & & & & 344.0 & 33 & 26 & \\
\hline \multirow[t]{2}{*}{ chlorfenvinphos } & $\mathrm{CFV}$ & 359.0 & 76 & 155.0 & 17 & 20 & 25 \\
\hline & & & & 99.0 & 43 & 8 & \\
\hline \multirow[t]{2}{*}{ chlorpyrifos } & CPE & 352.0 & 45 & 200.0 & 30 & 38 & 25 \\
\hline & & 350.0 & 61 & 198.0 & 21 & 12 & \\
\hline \multirow[t]{2}{*}{ diuron } & DIU & 233.0 & 46 & 72.1 & 51 & 6 & 25 \\
\hline & & & & 46.0 & 37 & 8 & \\
\hline \multirow{2}{*}{$\begin{array}{l}\text { 3,4- } \\
\text { dichloroaniline }\end{array}$} & DCA & 162.0 & 51 & 127.0 & 31 & 24 & 25 \\
\hline & & & & 74.0 & 73 & 14 & \\
\hline \multirow{4}{*}{$\begin{array}{l}\text { 3-(3,4- } \\
\text { dichlorophenyl)- } \\
\text { 1-methylurea } \\
\text { diflufenican }\end{array}$} & DCPMU & 218.7 & 66 & 162.1 & 21 & 26 & 25 \\
\hline & & & & 127.0 & 37 & 22 & \\
\hline & DFF & 395.0 & 86 & 266.0 & 35 & 28 & 25 \\
\hline & & & & 246.0 & 47 & 40 & \\
\hline \multirow[t]{2}{*}{ dimethomorph } & DMM & 388.0 & 76 & 301.2 & 31 & 36 & 25 \\
\hline & & & & 165.1 & 43 & 28 & \\
\hline \multirow[t]{2}{*}{ fenitrothion } & FNT & 277.9 & 71 & 124.8 & 29 & 22 & 25 \\
\hline & & & & 109.0 & 25 & 16 & \\
\hline \multirow[t]{2}{*}{ isoproturon } & IPU & 207.0 & 51 & 72.2 & 37 & 8 & 25 \\
\hline & & & & 165.0 & 19 & 28 & \\
\hline \multirow[t]{2}{*}{ linuron } & LINU & 249.0 & 61 & 160.0 & 25 & 32 & 20 \\
\hline & & & & 182.0 & 19 & 12 & \\
\hline \multirow[t]{2}{*}{ norflurazon } & NFZ & 304.0 & 101 & 284.0 & 35 & 26 & 25 \\
\hline & & & & 88.0 & 61 & 16 & \\
\hline \multirow[t]{2}{*}{ spiroxamine } & SPX & 297.9 & 51 & 144.3 & 31 & 8 & 20 \\
\hline & & & & 100.1 & 45 & 18 & \\
\hline procymidone & PCM & 284.0 & 76 & 256.0 & 25 & 46 & 25 \\
\hline \multirow[t]{2}{*}{ tebuconazole } & TBZ & 309.0 & 51 & 69.9 & 45 & 12 & 20 \\
\hline & & & & 125.1 & 53 & 22 & \\
\hline \multirow[t]{2}{*}{ diuron d6 } & DIU d6 & 239.0 & 66 & 78.0 & 43 & 14 & 30 \\
\hline & & & & 52.0 & 37 & 10 & \\
\hline \multirow[t]{2}{*}{ isoproturon d6 } & IPU d6 & 213.1 & 66 & 78.3 & 27 & 14 & 25 \\
\hline & & & & 171.2 & 21 & 10 & \\
\hline
\end{tabular}




\section{Table 2}

447

448

449

\begin{tabular}{|c|c|c|c|c|c|c|c|c|c|c|c|c|}
\hline \multicolumn{2}{|c|}{ Factors } & \multicolumn{11}{|c|}{ Responses } \\
\hline \multirow{3}{*}{$\begin{array}{l}\text { desorption } \\
\text { time (min) }\end{array}$} & \multirow{3}{*}{$\begin{array}{c}\mathrm{ACN} / \\
\mathrm{MeOH} \\
(\%)\end{array}$} & \multirow{3}{*}{$\begin{array}{l}\text { AZS } \\
(\%)\end{array}$} & \multirow{3}{*}{$\begin{array}{l}\mathrm{CPE} \\
(\%)\end{array}$} & \multirow{3}{*}{$\begin{array}{c}\text { DCA } \\
(\%)\end{array}$} & \multirow{3}{*}{$\begin{array}{c}\text { DCPMU } \\
(\%)\end{array}$} & \multirow{3}{*}{$\begin{array}{l}\text { DIU } \\
(\%)\end{array}$} & \multirow{3}{*}{$\begin{array}{c}\text { DMM } \\
(\%)\end{array}$} & \multirow{3}{*}{$\begin{array}{l}\text { FNT } \\
(\%)\end{array}$} & \multirow{3}{*}{$\begin{array}{l}\text { IPU } \\
(\%)\end{array}$} & \multirow{3}{*}{$\begin{array}{l}\text { LINU } \\
(\%)\end{array}$} & \multirow{3}{*}{$\begin{array}{l}\text { SPX } \\
(\%)\end{array}$} & \multirow{3}{*}{$\begin{array}{l}\text { TBZ } \\
(\%)\end{array}$} \\
\hline & & & & & & & & & & & & \\
\hline & & & & & & & & & & & & \\
\hline 30 & $0 / 100$ & 45.3 & 81.9 & 26.8 & 5.8 & 11.9 & 9.4 & 49.2 & 25.8 & 77.0 & 62.5 & 26.2 \\
\hline 5 & $50 / 50$ & 49.8 & 99.6 & 24.1 & 4.7 & 9.7 & 10.7 & 82.2 & 18.8 & 77.7 & 65.4 & 33.2 \\
\hline 15 & $50 / 50$ & 67.1 & 100.4 & 28.6 & 5.7 & 10.6 & 11.1 & 58.0 & 21.8 & 82.2 & 89.8 & 30.4 \\
\hline 5 & $100 / 0$ & 30.4 & 65.0 & 19.3 & 4.2 & 7.6 & 8.8 & 53.0 & 15.7 & 58.9 & 13.9 & 20.0 \\
\hline 15 & $50 / 50$ & 67.1 & 100.4 & 28.6 & 5.7 & 10.6 & 11.1 & 58.0 & 21.8 & 82.2 & 89.8 & 30.4 \\
\hline 15 & $100 / 0$ & 52.9 & 102.0 & 25.4 & 3.9 & 9.8 & 9.9 & 85.7 & 17.6 & 77.0 & 26.7 & 28.3 \\
\hline 30 & $100 / 0$ & 68.4 & 110.0 & 24.4 & 5.8 & 10.7 & 12.5 & 72.7 & 20.2 & 86.8 & 32.1 & 36.1 \\
\hline 30 & $50 / 50$ & 45.5 & 75.5 & 25.6 & 5.5 & 12.3 & 10.9 & 67.2 & 21.8 & 71.8 & 53.0 & 39.8 \\
\hline 5 & $0 / 100$ & 61.3 & 86.7 & 26.4 & 5.2 & 11.3 & 11.0 & 53.1 & 19.8 & 74.4 & 69.2 & 30.5 \\
\hline 15 & $0 / 100$ & 71.1 & 85.9 & 22.9 & 5.3 & 9.8 & 11.8 & 54.5 & 19.1 & 70.5 & 66.2 & 41.1 \\
\hline
\end{tabular}

Experimental design for desorption time and composition of the back-desorption solvent. Responses obtained for the selected pesticides are expressed in raw recoveries without matrix match calibration (spiking concentration: $1 \mu \mathrm{g} \cdot \mathrm{L}^{-1}$; SBSE: $3 \mathrm{~h}, 800 \mathrm{rpm}$ ). 
455 Linear

456

457

\section{Table 3}

concentration levels.

\begin{tabular}{|c|c|c|c|c|c|c|c|c|c|c|c|}
\hline \multirow[b]{2}{*}{ Compound } & \multirow[b]{2}{*}{$\begin{array}{l}\text { Concentration } \\
\text { range }\left(\mu \mathrm{g} \mathrm{L}^{-1}\right)\end{array}$} & \multirow{2}{*}{$\begin{array}{l}\text { Regression } \\
\text { coefficient }\left(\mathrm{r}^{2}\right)\end{array}$} & \multicolumn{3}{|c|}{ LOQ level } & \multicolumn{3}{|c|}{ Medium level } & \multicolumn{3}{|c|}{ High level } \\
\hline & & & $\begin{array}{l}\text { conc. } \\
\mu \mathrm{g} \mathrm{L}^{-1}\end{array}$ & $\begin{array}{l}\text { Recovery } \\
\text { (RSD) }(\%)\end{array}$ & $\begin{array}{c}\mathrm{U} \\
(\%)\end{array}$ & $\begin{array}{l}\text { conc. } \\
\mu \mathrm{g} \mathrm{L}^{-1}\end{array}$ & $\begin{array}{l}\text { Recovery } \\
\text { (RSD) }(\%)\end{array}$ & $\begin{array}{l}\mathrm{U} \\
(\%)\end{array}$ & $\begin{array}{l}\text { conc. } \\
\mu \mathrm{g} \mathrm{L}^{-1}\end{array}$ & $\begin{array}{l}\text { Recovery } \\
\text { (RSD) }(\%)\end{array}$ & $\begin{array}{l}\mathrm{U} \\
(\%)\end{array}$ \\
\hline AZS & $0.02-1.0$ & 0.9980 & 0.02 & $98.7(8.1)$ & 16.0 & 0.20 & $94.3(21)$ & 16.1 & 0.80 & $93.7(9.4)$ & 19.2 \\
\hline $\mathrm{CFV}$ & $0.10-5.0$ & 0.9990 & 0.10 & $96.1(12)$ & 23.5 & 1.0 & $98.4(22)$ & 17.3 & 4.0 & $92.6(7.4)$ & 14.8 \\
\hline $\mathrm{CPE}$ & $0.05-2.5$ & 0.9980 & 0.05 & $99.6(9.2)$ & 18.7 & 0.50 & $93.0(20)$ & 15.7 & 2.0 & $101(6.6)$ & 13.3 \\
\hline DIU & $1.0-50$ & 0.9990 & 1.0 & $97.3(9.8)$ & 19.7 & 10 & $89.3(23)$ & 17.8 & 40 & 99.8 (9.9) & 19.7 \\
\hline DCA & $0.05-2.5$ & 0.9987 & 0.05 & 95.7 (10) & 20.5 & 0.50 & $96.2(8.0)$ & 16.2 & 2.0 & $91.6(7.4)$ & 14.8 \\
\hline DCPMU & $1.0-50$ & 0.9972 & 1.0 & $98.4(7.1)$ & 14.3 & 10 & $94.2(21)$ & 13.5 & 40 & $95.4(9.0)$ & 18.2 \\
\hline DFF & $0.20-10$ & 0.9997 & 0.20 & 98.7 (11) & 21.8 & 2.0 & $92.2(22)$ & 18.3 & 8.0 & $90.8(6.9)$ & 13.9 \\
\hline DMM & $0.10-5.0$ & 0.9988 & 0.10 & $101(10)$ & 20.8 & 1.0 & $97.3(24)$ & 21.9 & 4.0 & $103(8.9)$ & 17.8 \\
\hline FNT & $0.50-25$ & 0.9958 & 0.50 & $96.0(8.7)$ & 17.5 & 5.0 & $92.9(22)$ & 16.1 & 20 & $93.6(10)$ & 20.0 \\
\hline IPU & $0.10-5.0$ & 0.9982 & 0.10 & $95.5(11)$ & 21.9 & 1.0 & $96.9(25)$ & 19.1 & 4.0 & $88.7(9.4)$ & 19.0 \\
\hline LINU & $0.10-5.0$ & 0.9989 & 0.10 & $97.9(8.9)$ & 17.9 & 1.0 & $95.1(22)$ & 16.2 & 4.0 & $95.0(11)$ & 21.6 \\
\hline NFZ & $0.20-10$ & 0.9985 & 0.20 & $95.4(8.5)$ & 16.9 & 2.0 & $100(21)$ & 11.5 & 8.0 & $95.8(7.4)$ & 15.1 \\
\hline PCM & $0.20-10$ & 0.9995 & 0.20 & $105(6.7)$ & 13.4 & 2.0 & $95.9(20)$ & 19.8 & 8.0 & $102(7.3)$ & 14.6 \\
\hline SPX & $0.02-1.0$ & 0.9990 & 0.02 & $96.0(8.0)$ & 16.2 & 0.2 & $92.2(22)$ & 16.7 & 0.80 & $91.1(11)$ & 21.5 \\
\hline TBZ & $0.10-5.0$ & 0.9989 & 0.10 & $100(11)$ & 21.3 & 1.0 & $96.1(23)$ & 16.6 & 4.0 & $96.7(12)$ & 23.5 \\
\hline
\end{tabular}




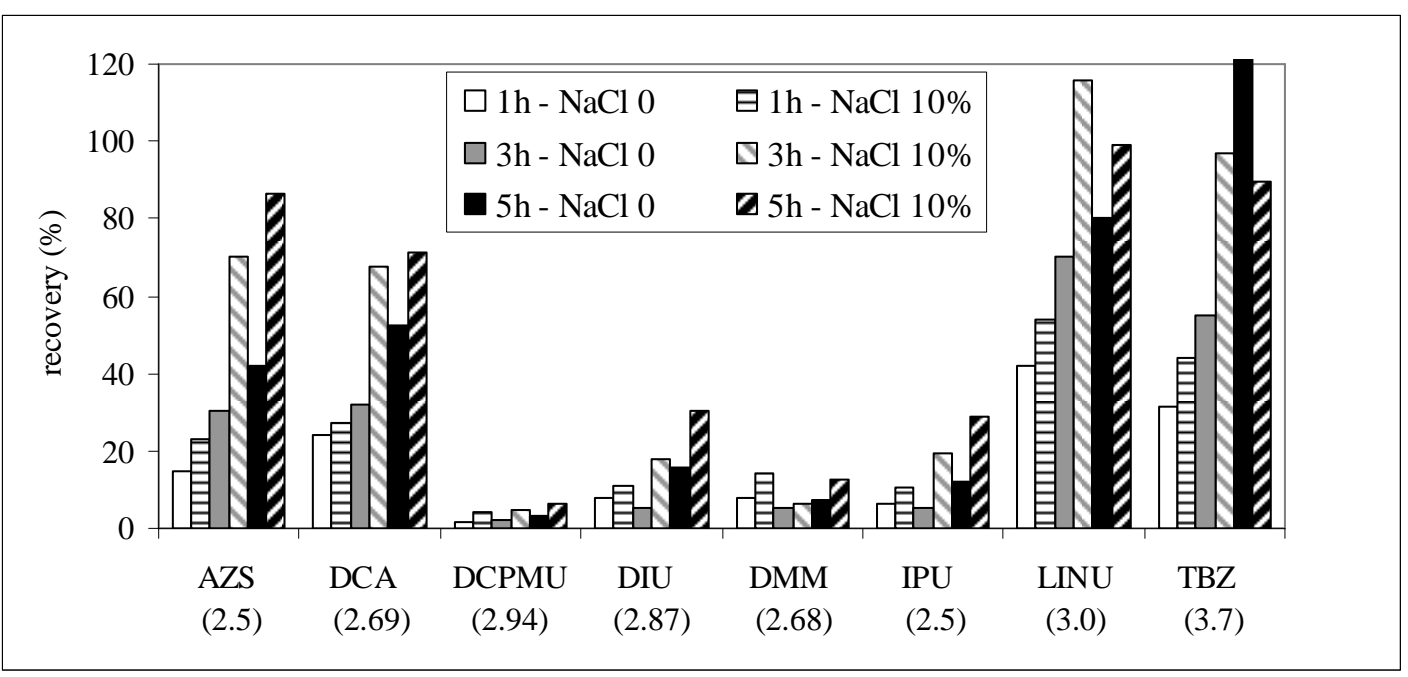

Fig. 1. Effect of extraction time and $\mathrm{NaCl}$ addition on recoveries of the selected pesticides after SBSELD-LC-MSMS (desorption solvent: ACN/MeOH 50:50; desorption time: $15 \mathrm{~min}$ ). Numbers in brackets on the $\mathrm{x}$ axis are the octanol-water partition coefficient of the studied pesticides (log Kow).

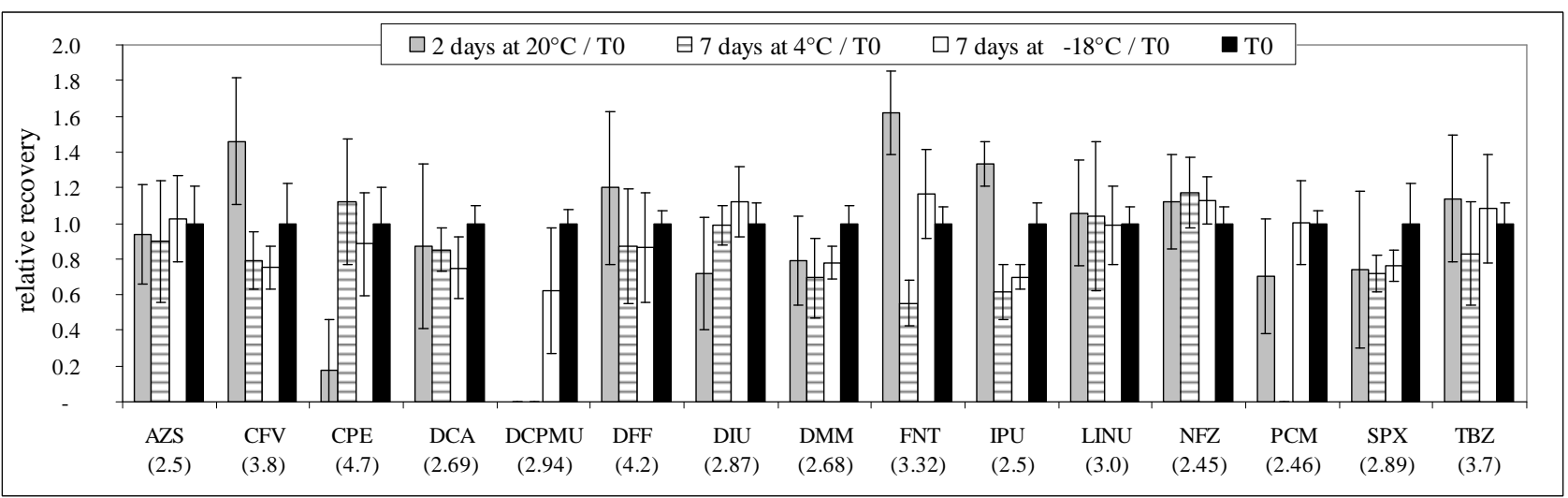

Fig. 2. Relative recoveries (compared to T0) of pesticides absorbed on stir bars and stored in different conditions (temperature and duration). Numbers in brackets on the $\mathrm{x}$ axis are the octanol-water partition coefficient of the studied pesticides ( $\log$ Kow). Error bars represent $\pm s, n=3$. 


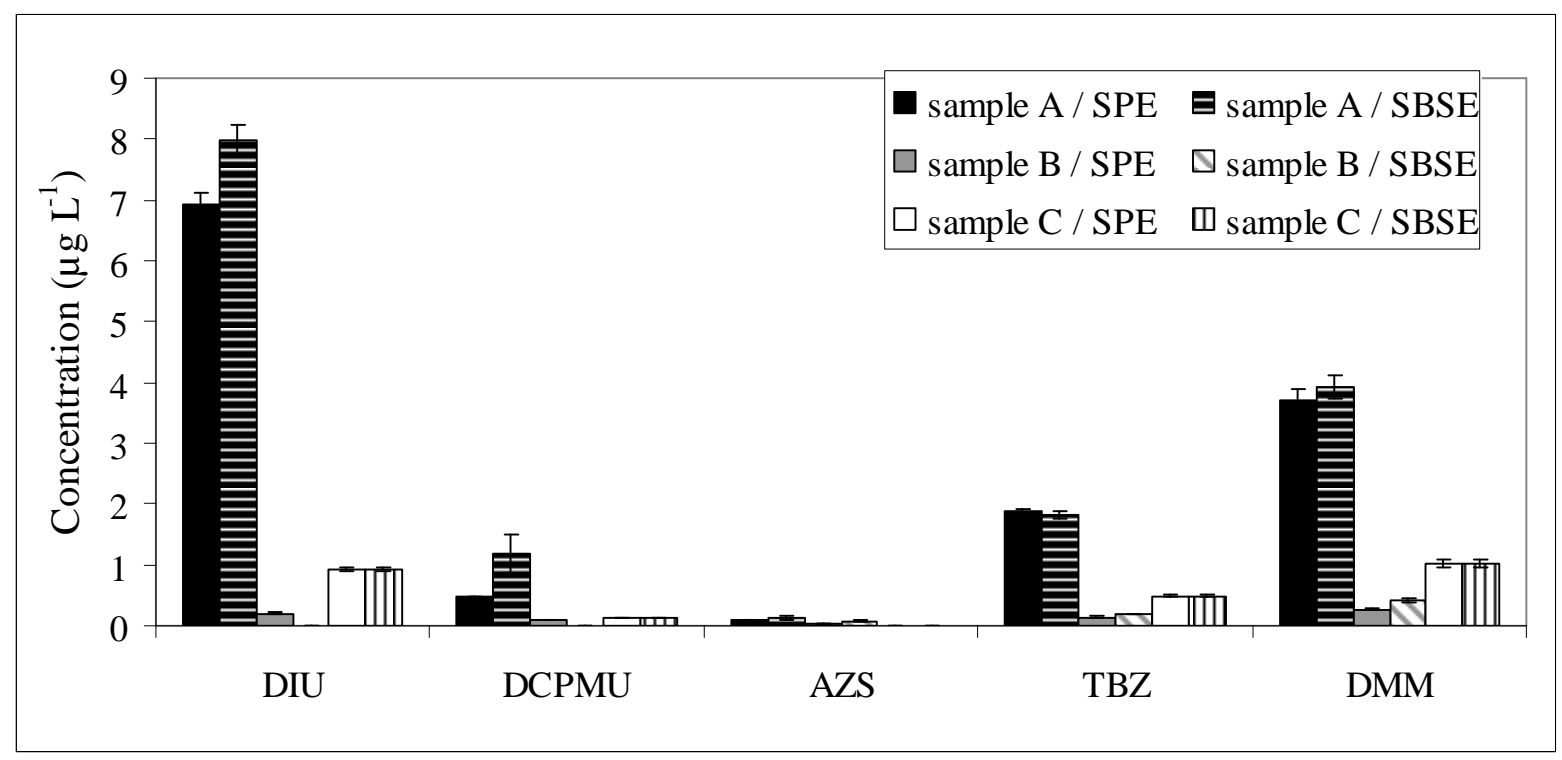

Fig. 3. Comparison between SPE-LC-MSMS and SBSE-LD-LC-MSMS for 3 filtered surface water samples. Only detected pesticides are represented. Error bars represent $\pm s, n=3$.

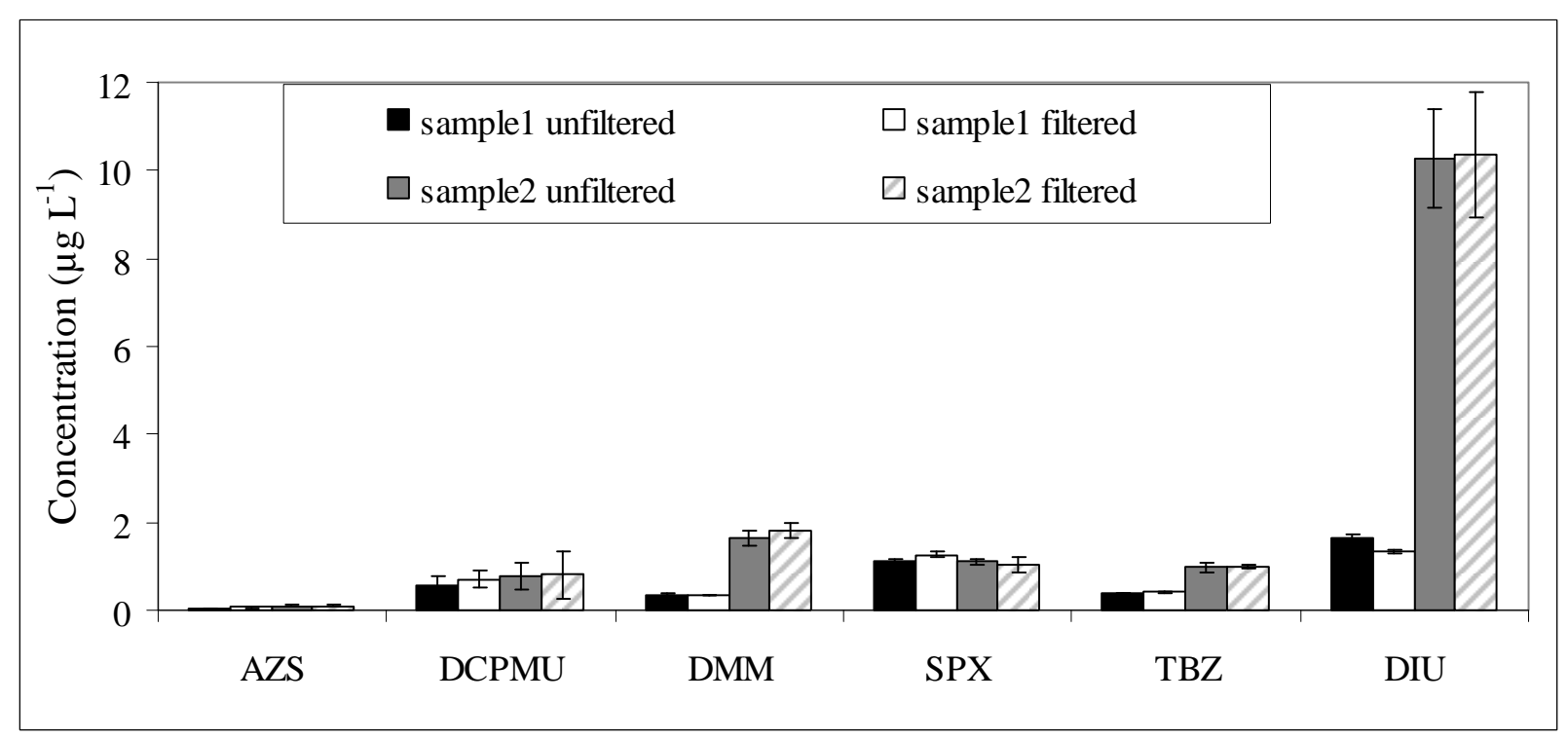

Fig. 4. Application of SBSE-LD-LC-MSMS on 2 surface water samples, filtered or not, before extraction. Only detected pesticides are represented. Error bars represent $\pm s, n=3$. 